\title{
Brugada Syndrome-Like ST-Segment Elevation Increase Exacerbated by Vomiting
}

\author{
Mariko Arai, MD; Kiyoshi Nakazawa, MD; Akihiko Takagi, MD; Ryoji Kishi, MD; \\ Keizo Osada, MD; Syonosuke Ryu, MD; Fumihiko Miyake, MD
}

\begin{abstract}
The patient was a 53 year-old male who had 3 syncopal episodes over a 6-month period. In the electrophysiological study, ventricular fibrillation (VF) was repeatedly induced by the ventricular extrastimulus method. Intravenous pilsicainide was administered, and the J-point and ST-segment in the right precordial leads became slightly elevated just following drug administration. Five min later, the patient experienced severe nausea and then vomited twice, at which point the electrocardiogram (ECG) showed increased elevation of the J-point and STsegment. These ECG changes recovered to normal $30 \mathrm{~min}$ later. The cause of his syncope was strongly suspected to be related to the VF associated with Brugada syndrome. An interesting aspect of this case was the particular type of J-point and ST-segment elevation that was induced when the patient experienced nausea and vomiting. It is proposed that this phenomenon originated from the vagal stimulation associated with the nausea and vomiting. (Circ J 2004; 68: 712-714)
\end{abstract}

Key Words: Brugada syndrome; Pilsicainide; ST-segment; Vagal activity; Vomiting

B rugada syndrome is a sudden cardiac death syndrome $^{1-3}$ that has the specific electrocardiographic (ECG) features of J-point elevation and ST-segment elevation, which are believed to result from a disturbance of the Na channel in the myocardium? Normally, these typical ECG features are transient, but the contributory factors to their development remain unclear.

We describe a case of transient Brugada syndrome-like ST-segment elevation that was exacerbated by nausea and vomiting.

\section{Case Report}

The patient was a 53 year-old male who had been hospitalized for the treatment of syncope 3 times in the preceding 6 months. The cause of his symptoms was not apparent and consequently a cardiac origin was investigated. The ECG on admission exhibited a normal axis, slight prolongation of the QRS width (0.12 s), slight ST segment elevation $(0.1 \mathrm{mV})$ suggestive of early repolarization in the right precordial leads, normal QT interval, and no ischemic ST-T changes. These ECG findings did not change under normal conditions and both Holter ECG monitoring and echocardiography revealed normal cardiac function. The treadmill test revealed horizontal ST-segment depression in leads II, III, $\mathrm{aV}_{F}, \mathrm{~V}_{5}$ and $\mathrm{V}_{6}$, which suggested ischemic heart disease. Cardiac catheterization demonstrated a $75 \%$ stenosis of the mid portion of the right coronary artery, and normal left and right ventriculography. Acetylcholine administration into the coronary arteries $(50 \mu \mathrm{g}$ and $100 \mu \mathrm{g}$ of ACh in the right and left coronary arteries, respectively)

(Received February 21, 2002; revised manuscript received November 21, 2002; accepted November 27, 2002)

Division of Cardiology, Department of Internal Medicine, St Marianna University School of Medicine, Kawasaki, Japan

Mailing address: Mariko Arai, MD, Division of Cardiology, Department of Internal Medicine, St Marianna University School of Medicine, 2-16-1 Sugao, Miyamae-ku, Kawasaki 216-8511, Japan induced spasm (a stenosis of 50\%) in the posterior descending and left anterior descending arteries. However, there were no changes recorded on the ECG during ACh administration. Percutaneous transluminal coronary angioplasty of the right coronary artery was successful.

An electrophysiological study (EPS) was performed 1 week later in which ventricular fibrillation (VF) was repeatedly induced by the ventricular extrastimulus method ( 2 paired extrastimuli). Intravenous pilsicainide $(1 \mathrm{mg} / \mathrm{kg}$ ) was followed by slight elevation of the J-point and STsegment in the right precordial leads, which suggested that Brugada syndrome was responsible for the VF (Fig 1). Five min later, the subject experienced severe nausea and vomited twice during which the ECG showed an increased elevation of the J-point and ST-segment (Fig 2). These ECG changes recovered to normal 30 mins later; the nausea and vomiting improved after the second vomiting episode. One week later, pilsicainide administration $(1 \mathrm{mg} / \mathrm{kg})$ was repeated (Fig 3), and the J-point and ST-segment slightly elevated, but nausea and vomiting did not occur. The ECG changes improved $30 \mathrm{~min}$ after the administration of pilsicainide without any further significant J-point or STsegment elevation.

An implantable cardioverter defibrillator (ICD) was implanted and a calcium channel blocker was prescribed. A tilt test $\left(60^{\circ}\right.$ tilting) was performed 1 week after the ICD implantation and neither blood pressure nor heart rate changed significantly during either the control state or with isoproterenol administration. For 10 months, the patient has been free of both syncopal episodes and VF.

The patient gave informed consent for all investigations and therapies.

\section{Discussion}

The cause of the syncope experienced by the present patient was strongly suspected to be related to VF associated with Brugada syndrome. However, arrhythmia related to 


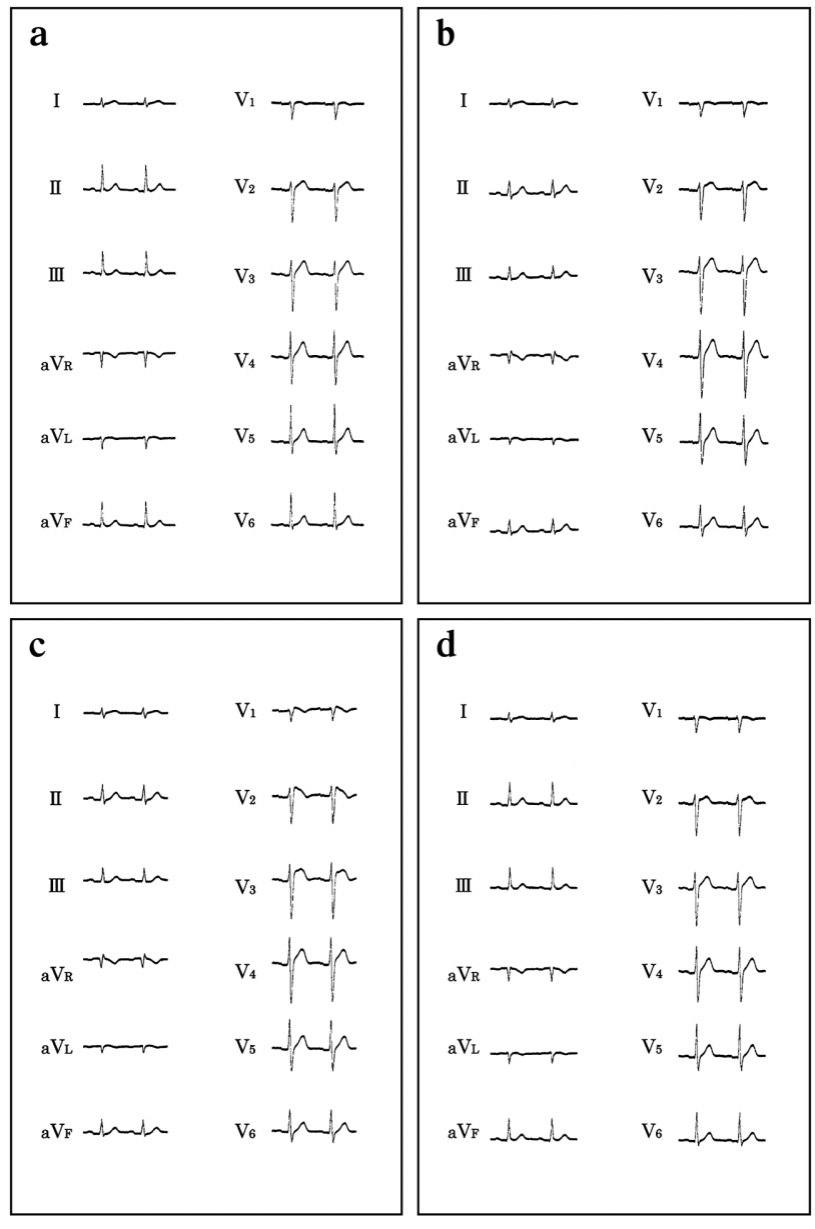

Fig 1. ECG changes produced by the first administration of intravenous pilsicainide $(1 \mathrm{mg} / \mathrm{kg}$ ). (a) Before administration. (b) After administration: the J-point and ST-segment in the right precordial leads are slightly elevated. (c) Five min later, the ECG shows increased elevation in the J-point and ST-segment when the patient developed severe nausea and vomited twice. (d) The ECG changes have returned to normal after $30 \mathrm{~min}$.

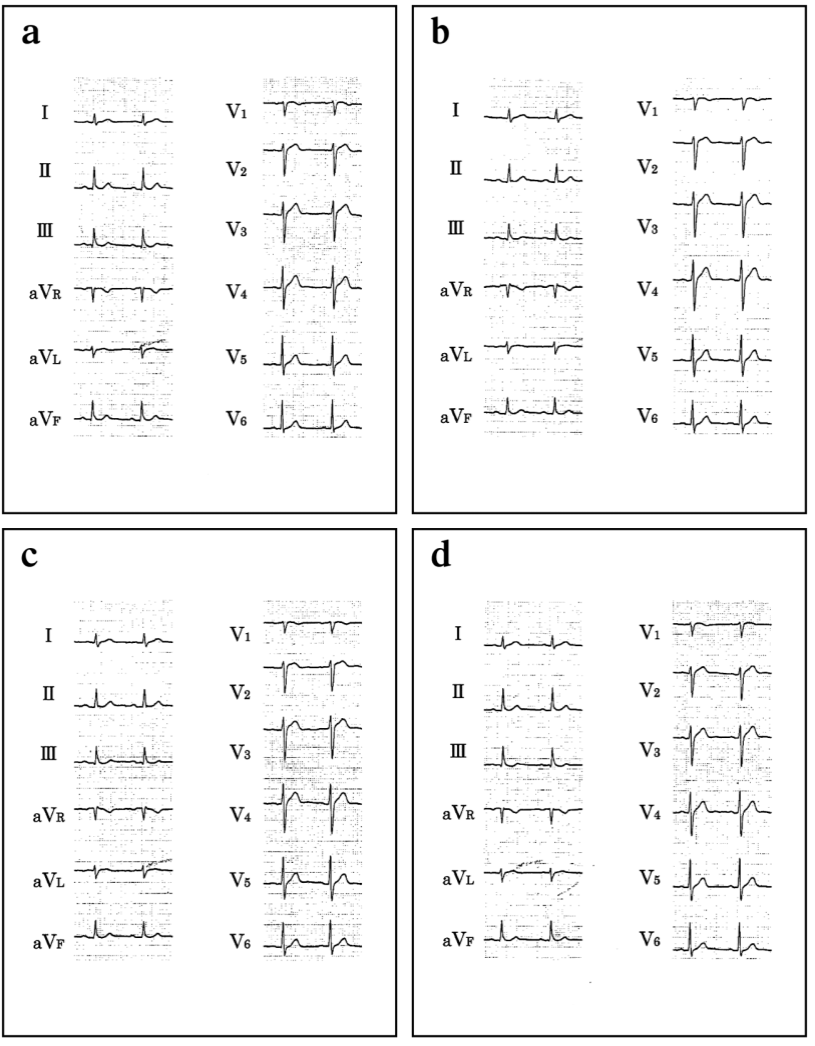

Fig 3. ECG change observed during the second administration of intravenous pilsicainide $(1 \mathrm{mg} / \mathrm{kg}$ ). (a) Before administration of pilsicainide. (b) After administration of pilsicainide: the J-point and STsegment in the right precordial leads are slightly elevated. (c) Five min after the administration of pilsicainide. (d) The ECG changes have improved $30 \mathrm{~min}$ after the administration of pilsicainide. a

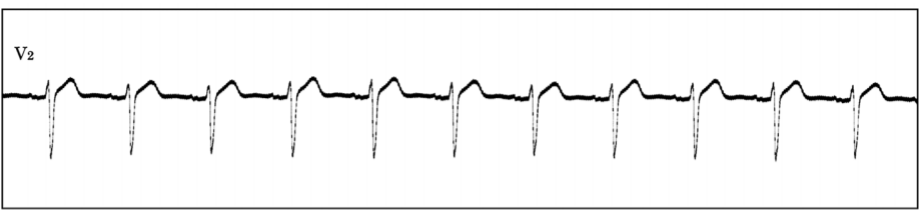

b

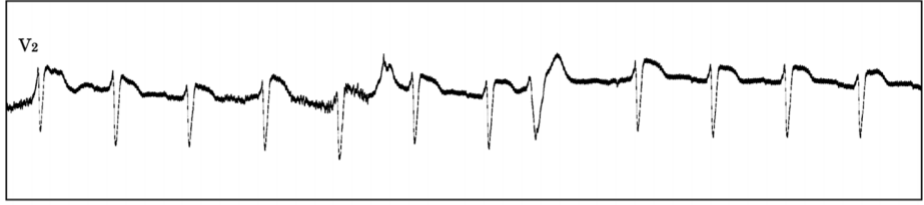

c

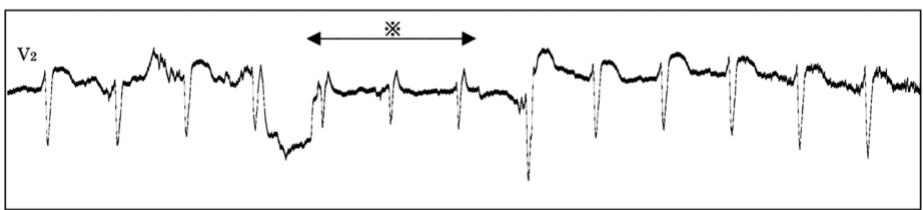

d

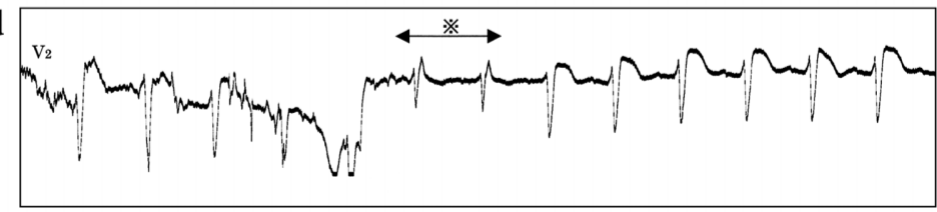

Fig 2. Change in the $\mathrm{V}_{2}$ lead after intravenous pilsicainide $(1 \mathrm{mg} / \mathrm{kg})$ (a) when the patient had no symptoms, (b) during severe nausea, and during (c) the first episode and (d) the second episode of vomiting. (※ The STsegment was not elevated during these heart beats, which we believe is related to the influence of posture change on the relative location between the electrodes and the heart.) 
coronary artery disease was also suspected, which is why we prescribed a calcium channel blocker in conjunction with ICD implantation. The underlying mechanism of the J-point and ST-segment elevation in Brugada syndrome is believed to be related to a transmural repolarization gradient in the right ventricle, based on an imbalance between the outward and inward currents (ie, outward $>$ inward $)^{5}$ that is affected by sodium channel blockers and vagal activity 6

An interesting aspect of the present case was the particular type of J-point and ST-segment elevation (ie, typical Brugada syndrome-like ECG morphology; coved type STsegment elevation) that was induced when the patient felt nauseous and vomited. We propose that this phenomenon originated from a strong autonomic change. Sympathetic stimulation decreases ST-segment elevation, 6,7 whereas it is believed that vagal stimulation contributes to ST-segment elevation and the occurrence of $\mathrm{VF}^{6,8} \mathrm{We}$ also propose that the ECG changes originated from the vagal stimulation associated with the nausea and vomiting, because significant ECG changes were not observed during the second pilsicainide administration trial in which those symptoms did not occur. Though the cause of the nausea and vomiting is unknown, the symptoms completely and quickly improved without any treatment.

To the best of the our knowledge, this is the first report of Brugada syndrome-like ECG changes induced by nausea and vomiting.

\section{References}

1. Brugada P, Brugada J. Right bundle branch block, persistent ST segment elevation and sudden cardiac death: A distinct clinical and electrocardiographic syndrome. J Am Coll Cardiol 1992; 20: 1391 1396.

2. Itoh H, Shimizu M, Ino H, Okeie K, Yamaguchi M, Fujino N, et al Hokuriku Brugada Study Group. Arrhythmias in patients with Brugada-type electrocardiographic findings. Jpn Circ J 2001; 65: $483-486$.

3. Nanke T, Nakazawa K, Arai M, Ryuu S, Osada K, Sakurai T, et al. Clinical significance of the dispersion of the activation-recovery interval and recovery time as markers for ventricular fibrillation susceptibility in patients with Brugada syndrome. Circ J 2002; 66: 549552.

4. Chen Q, Kirsch GE, Zhang D, Brugada R, Brugada J, Brugada P, et al. Genetic basis and molecular mechanism for idiopathic ventricular fibrillation. Nature 1998; 392: 293-296.

5. Gussak I, Antzelevitch C, Bjerregaard P, Towbin JA, Chaitman BR. The Brugada syndrome: Clinical, electrophysiologic and genetic aspects. J Am Coll Cardiol 1999; 33: 5-15.

6. Miyazaki T, Mitamura H, Miyoshi S, Soejima K, Aizawa Y, Ogawa S. Autonomic and antiarrhythmic drug modulation of ST segment elevation in patients with Brugada syndrome. $J$ Am Coll Cardiol 1996; 27: 1061-1070.

7. Nakazawa K, Tohyo Y, Takagi A, Matsumoto M, Sakurai T, Miyake F. The electrophysiological mechanism of the right bundle branch block-like ECG morphology in patients with Brugada syndrome: Is the late R wave-like ECG morphology caused by a conduction or repolarization abnormality? St Marianna Med J 2000; 28: 247-259.

8. Kasanuki H, Ohnishi S, Ohtuka M, Matsuda N, Nirei T, Isogai R, et al. Idiopathic ventricular fibrillation induced with vagal activity in patients without obvious heart disease. Circulation 1997; 95: 2277 2285. 